Linguagem em (Dis)curso - LemD, v. 9, n. 1, p. 11-34, jan./abr. 2009

\title{
SUJEITO, DISCURSO E VIDA URBANA: UM ESTUDO CONTRASTIVO DE DISCURSOS SOBRE A EXCLUSÃO SOCIAL NO BRASIL E NA ESPANHA
}

\author{
Anna Elizabeth Balocco* \\ Maria Labarta Postigo**
}

\begin{abstract}
Resumo: Neste artigo, apresenta-se um estudo contrastivo de discursos sobre a exclusão social através da análise de videoclipes produzidos por mulheres rappers no Brasil e na Espanha, segundo princípios da Análise Crítica do Discurso e com foco na construção da identidade. A análise das práticas de identificação das rappers sugere que a alteridade se expressa de forma distinta nos dois discursos: enquanto o "outro" articula-se, no discurso da rapper brasileira, através de estratégias léxico-gramaticais de indeterminação ("essa gente") ou abstração ("a sociedade"), no da rapper espanhola há estratégias de funcionalização ("os políticos") e objetivização ("o dinheiro"). Ou seja, há mais indeterminação do "outro" no caso da rapper brasileira.

Palavras-chave: gênero social; identidade; exclusão social; música; videoclipe.
\end{abstract}

\section{INTRODUÇÃO}

Os discursos sobre a exclusão social ganharam visibilidade no cenário internacional nos anos 90, a partir de um conjunto de acontecimentos globais que se situam no quadro do que se convencionou chamar de 'o mundo pós-colonial'. Desde o fim dos Estados coloniais, observa-se um cenário marcado pela expressão de

\footnotetext{
* Professora da Universidade do Estado do Rio de Janeiro. Doutora em Linguística. E-mail: <annabalocco@terra.com.br>.

** Professora da Universidade de Valencia. Doutora em Linguística. E-mail: <maria.labarta@uv.es>.
} 
grupos minoritários, que vivem nas periferias do mundo capitalista (VENTURA, 2005, p. 79).

No Brasil, por exemplo, observa-se a emergência de representações, na mídia em geral, sobre a exclusão social a partir de alguns marcos, como os famosos "arrastões" de 1992/1993 nas praias cariocas (HERSCHMANN, 2005, p. 19); o episódio do massacre de presos no presídio Carandiru em São Paulo (02 de outubro de 1992); o Massacre da Candelária (em 1993, oito crianças de rua foram assassinadas pela polícia no Rio de Janeiro em frente à Igreja da Candelária); o assassinato da líder do movimento Mães de Acari, movimento que denunciava o assassinato de menores e trabalhadores em favelas (agosto de 1993) - dentre vários outros (VENTURA, 2005, p. $80)$.

Do ponto de vista da cena cultural no Brasil, observa-se, na década de 90, um verdadeiro "boom" de produções nas mais variadas esferas da vida artística (cinema, literatura, dança) voltadas para a representação de grupos minoritários (PEREIRA, 2006, p. 325). Destacam-se, desta produção, os filmes "Central do Brasil" (1998) de Walter Moreira Salles, "Carandiru" (2003) de Hector Babenco, "Amarelo Manga" (2003), de Cláudio Assis; os livros "Cidade de Deus" (1997) de Paulo Lins e "Manual Prático do Ódio" (2005), de Ferréz. Não se pode desprezar, ainda, segundo Pereira, uma "estética documental" na literatura, em que se incluem obras como "Cabeça de Porco" (2005), de Luiz Eduardo Soares, MV Bill e Celso Athaíde, "Falcão - meninos do tráfico" (2006), publicado por MV Bill e Celso Athaíde e "Elite da Tropa" (2006), de Luiz Eduardo Soares em parceria com André Batista e Rodrigo Pimentel. Todas estas obras tematizam o tráfico de drogas em comunidades de baixa renda e adotam o formato documental, alternando depoimentos de moradores com trechos analíticos, em que os autores elaboram teoricamente alguns pontos tematizados ou apresentam propostas de recuperação das crianças e jovens daquelas comunidades.

Há, segundo Pereira (2006, p. 328), mesmo na mídia televisiva (entendida como uma instância discursiva das mais conservadoras no Brasil), a emergência deste discurso consensual, voltado para "tornar visível o pobre e a pobreza no Brasil". Em 2006, entrava no ar o programa "Periferias", liderado pela atriz Regina Casé, que visita comunidades periféricas com o objetivo de divulgar a sua cultura. Estas

BALOCCO; POSTIGO - Sujeito, discurso e vida urbana... 
visitas não se restringem ao território nacional, mas têm alcançado locais como Maputo, em Moçambique, dentre vários outros.

É no bojo de tendências mundiais que dão visibilidade a discursos sobre a exclusão social, nos anos 90, que o movimento hip-hop consolida-se como estética dominante na música pop. Embora seja um produto da cultura norte-americana da década de 70, o movimento é absorvido por jovens de comunidades periféricas em centros urbanos em escala global e transformado em produto nacional, associando-se a significantes da cultura local.

As canções rap em espanhol, por exemplo, surgem nas comunidades latinas dos Estados Unidos, para se expandir para diferentes países de língua espanhola. Na Espanha, é um fenômeno cultural relativamente recente, numa cena dominada por homens. Embora seja um fenômeno de grande impacto na cultura popular, ainda não pode ser considerado um fenômeno de massas como em outros países.

Neste artigo, apresenta-se um estudo contrastivo de discursos sobre a exclusão social no Brasil e na Espanha, a partir de uma análise de canções produzidas por mulheres rappers. Estas produções artísticas na contemporaneidade podem ser entendidas como a superfície discursiva onde se inscrevem demandas de representação de grupos minoritários. Vários autores têm procurado demonstrar que a luta pelo reconhecimento de um determinado estilo de vida é uma luta política, que pode levar à legitimação de novas formas de participação na sociedade.

As perguntas que norteiam esta pesquisa podem ser assim formuladas: que sentidos são atribuídos à figura da mulher Rapper, entendida como significante de exclusão social, em diferentes cenários locais (no Brasil e na Espanha)? Quais os possíveis eixos que, na construção da identidade da mulher rapper, norteiam suas práticas de identificação - identificação com a raça ou etnia? com a geração jovem? identificação com o caráter político e social do movimento hip-hop? Como se articulam estas práticas com um tipo específico de relação de poder, as relações de gênero? Que estereótipos do masculino e do feminino são construídos ou reforçados nestas produções musicais? 
A relevância deste projeto justifica-se face ao fato de que poucos são os trabalhos que se detêm no exame dos discursos sobre a exclusão social a partir da perspectiva das classes populares. Já no caso do movimento hip-hop, observa-se uma situação inédita, em que jovens de segmentos populares são emissores de discursos sobre a exclusão social.

\section{SUPORTE TEÓRICO}

Duas premissas básicas orientam este estudo. Em primeiro lugar, a música não fala da história de um indivíduo, mas da história do seu tempo. Sendo assim, investigar os sentidos inscritos em produções musicais pressupõe explorar as inter-relações complexas entre música e vida social. Em segundo lugar, as produções musicais são entendidas sob duas perspectivas: a) do viés de uma política de identidades, caso em que a produção cultural é vista como estratégia política de aglutinação e nomeação, com o objetivo de se estabelecer um lugar de fala e de ação para grupos sociais minoritários (RAJAGOPALAN, 2002); b) do ponto de vista da forma como constroem discursivamente a questão da "diferença social": os textos, como parte integrante de práticas sociais, podem acentuar ou minimizar, simbolicamente, as diferenças constitutivas do social (FAIRCLOUGH, 2003, p. 41). Assim, há textos que buscam 'normalizar' ou suprimir as diferenças (é o caso, por exemplo, de textos normativos cujo propósito é construir o "consenso"), enquanto outros acentuam as diferenças, o conflito, a polêmica.

Esta reflexão será desenvolvida tomando-se como ponto de partida a contribuição dos estudos na área da Análise Crítica do Discurso (doravante $\mathrm{ACD}$ ) para a teorização sobre questões relativas ao sujeito, a partir da problemática da identidade, nas suas dimensões de identidade social e de subjetividade (FAIRCLOUGH, 2003).

Para a ACD, o "outro" - entendido, nos termos de Zizek (2005, p. 49), como uma instância em relação à qual o sujeito é exterior e descentrado - é constitutivo da identidade. A necessidade de teorização a respeito da alteridade na sua relação com a identidade emerge, na ACD, a partir da noção de que "os antagonismos e divisões sociais são [vistos como] constitutivos do social” (LACLAU, 2007, p. 114). 
As produções musicais na contemporaneidade são acompanhadas de um traço característico que diz respeito à sua forma de distribuição e de circulação: elas têm como suporte o videoclipe, geralmente entendido como a versão visual de uma produção musical. Destacar uma canção de sua versão visual significa perder a chance, preciosa para um analista do discurso, de analisar uma prática social característica da contemporaneidade: alguns autores chegam a afirmar que o discurso videográfico modifica nossas experiências perceptivas e nossa forma de nos relacionarmos com o mundo (JANOTTI JR., 1994). O videoclipe não é mais visto apenas como uma estratégia de marketing (MENDONÇA, 2003), mas como uma prática social da contemporaneidade, que inaugura uma nova forma de interação social, possibilitada pelas novas tecnologias.

Sendo assim, tomamos como objeto de estudo o discurso videográfico musical alinhado ao movimento hip-hop, no Brasil e na Espanha. Embora se apresente numa pluralidade de formas, o videoclipe pode, por seus "elementos estabilizadores", ser visto como um gênero do discurso midiático, cujos traços principais, segundo Soares (2004), seriam: a) a noção de recorte (clip), que remete ao fato de que a imagem que ilustra o videoclipe é apenas uma "amostra" (entendida tanto no sentido de sample, amostra para vendagem, quanto no sentido de imagem recortada, ou parte de um todo); b) o ritmo acelerado das suas imagens; c) a descontinuidade das imagens, que se apresentam como entidades autônomas umas em relação às outras; e d) falta de vínculo associativo entre imagens e parte sonora e verbal. Para Pontes (2003), deve-se acrescentar ainda um importante elemento do discurso videográfico: enquanto no cinema os diferentes estilos servem para criar determinado tipo de narrativa (uma narrativa romântica, por exemplo, exige uma câmera lenta em várias sequências ou planos), no videoclipe o uso de diferentes estilos é aleatório: as diferentes formas de filmar apresentamse "desligadas do tipo de narrativas", sendo usadas como formas lúdicas de expressão.

Estes elementos constitutivos do videoclipe fazem emergir, segundo Soares (2004), uma "estética da superficialidade", que contrasta com a lógica da narrativa linear, da representação, dos encadeamentos, obervada no cinema. Para outros pesquisadores, o discurso videográfico obedece a uma "estética surrealista": o vídeo constrói um mundo de 


\section{6}

sonhos, fragmentado, através de imagens que causam estranhamento (OLIVA, 2005). $\mathrm{Na}$ análise dos videoclipes em discussão neste artigo, será discutido até que ponto os mesmos apresentam as características genéricas aqui descritas.

\section{METODOLOGIA}

A metodologia tomou como ponto de partida categorias discursivas postuladas para a análise da linguagem verbal (discurso, identidade), mas foi necessário ampliar o escopo da análise para dar conta dos diferentes recursos semióticos usados na construção do discurso videográfico: a sonoridade (o musical); a letra da canção (o verbal); a imagem (o visual). Assim, elegeu-se o quadro teórico da multimodalidade de Kress e Van Leeuwen (2001), voltado para as relações entre linguagem (ou linguagens: verbal, visual, sonora) e ideologia, na tradição dos estudos anglo-saxônicos do discurso a partir de uma perspectiva crítica.

Este quadro teórico foi complementado por categorias de Carnevacci (apud SOARES, 2004), tendo em vista que os estudos de multimodalidade não fornecem elementos para a análise da imagem em movimento, sequer de elementos da linguagem sonora. A seguir, apresentam-se as categorias analíticas, organizadas segundo proposta de Carnevacci:

a) linguagem sonora: aqui foram observados dois aspectos - o primeiro deles relacionado à música propriamente dita ou à dimensão das sonoridades, buscando-se responder às seguintes perguntas relacionadas às formas musicais empregadas: música mais ou menos melódica? mais ou menos rítmica? O segundo diz respeito aos ruidos, ou sons do cotidiano que figuram no videoclipe em discussão, importantes na construção de um entorno afetivo para a sua cena discursiva.

b) linguagem corporal: também foi considerada necessária uma categoria que remetesse aos gestos, fisionomias, roupas e 
expressões de corpo dos participantes discursivos, levando-se em conta o seu papel na caracterização da cena discursiva;

c) linguagem cromática: Kress e Van Leeuwen apontam a importância das cores na construção de significados simbólicos em imagens estáticas; os princípios dos autores são aplicados às imagens em movimento;

d) linguagem visual: aqui será necessário distinguir as seguintes categorias: a) estruturação discursiva - como se estrutura o discurso videográfico? Para responder a esta questão, será necessário abordar categorias como enquadramento, zoom, planos e sequencias, todas oriundas da teoria do cinema, mas já estudadas a partir de abordagens discursivas, que destacam o seu papel na construção do ponto de vista ou perspectiva discursiva (ANDRINGA et alii, 2001); b) cenário - que elementos materiais são usados no cenário? qual é a figuração da cena discursiva, ou seus participantes discursivos? c) quadro temporal - há elementos que permitem a ancoragem temporal da cena discursiva?

e) linguagem verbal: como em discursos fílmicos, é preciso diferenciar entre a voz off, em que são feitos comentários dirigidos diretamente ao espectador por uma voz "desencarnada", que não comparece à cena discursiva; e a voz in, que representa a fala de um participante discursivo, em geral, no caso de videoclipes, expressa através da letra da música.

Foi ainda necessário eleger uma categoria analítica para o estudo da linguagem verbal, de forma a evitar o risco de uma análise meramente conteudística. A categoria escolhida foi encontrada em estudos de Van Leeuwen (1996) sobre a representação de atores sociais no discurso. Neste quadro teórico, volta-se a atenção para a forma como são feitas referências, num conjunto de textos, aos participantes de determinado evento discursivo. Do ponto de vista empírico, são vários os atores sociais envolvidos num determinado processo social, mas do ponto de vista discursivo, apenas alguns destes atores estarão representados num texto. Interessa, portanto, analisar que atores sociais figuram, ou são efetivamente representados, no texto, e a forma como são representados 
(nomeados, classificados, codificados léxico-gramaticalmente através de referência genérica, específica, dentre outras possibilidades).

O corpus é constituído de três videoclipes (veja letras das músicas em anexo, ao final do artigo), um deles por uma rapper brasileira e os outros dois por uma rapper espanhola, de origem dominicana. Além destes vídeos, foram utilizados materiais encontrados na internet (entrevistas e letras de canções) que funcionaram como um corpus paralelo, para fundamentar a análise das canções do corpus principal. Os critérios na escolha do corpus prenderam-se, em primeiro lugar, ao papel das cantoras no movimento hip-hop, seguido pelo critério de acessibilidade ao material. Os seguintes dados, colhidos em sites alinhados ao movimento, apontam o papel de Nega Gizza na cena contemporânea: a cantora é carioca, tem 25 anos, irmã de MV Bill, produz documentários com a cineasta Katia Lund e é uma das fundadoras da Central Única das Favelas, movimento que organiza ações culturais em comunidades periféricas.

A rapper Arianna Puello (Ari), por sua vez, é descrita como a primeira mulher da cena espanhola, com um trabalho artístico iniciado em 1993. A cantora afirma nas suas entrevistas que começou motivada pela ausência de mulheres no mundo hip-hop.

\section{AS ANÁLISES: O CASO DA RAPPER BRASILEIRA}

O primeiro vídeo de Nega Gizza é uma produção aparentemente não-profissional veiculada na internet, que tematiza uma mulher em depressão. Este videoclipe foge, em muitos sentidos, às convenções do gênero (SOARES, 2004): sua estética é realista e não neobarroca ou surrealista, como vídeos veiculados na televisão. Assim, as linguagens cromática, corporal e visual reforçam a linguagem verbal, no sentido de representar realisticamente a depressão tematizada na letra da música. As cores escuras escolhidas na ambientação do cenário; a fisionomia tensa da cantora em planos fechados, com close-ups; a estruturação discursiva do vídeo em sequências encadeadas num só ambiente (um cômodo e uma escada de uma casa); algumas imagens desfocadas, escuras, com planos tremidos; tudo contribui para o efeito de sentido de 
enclausuramento, reduplicado na letra da música, analisada adiante. Do ponto de vista interacional, os close-ups na cantora têm como efeito de sentido criar empatia e aproximação com a protagonista.

Em geral, as imagens não representam associativamente a parte sonora e a verbal, mas, neste videoclipe, todas as linguagens convergem no sentido de reforçar os vínculos associativos entre imagem, texto e música. Por exemplo, há uma ocorrência de voz off no início, dizendo "estou sozinho", além de várias vozes destorcidas, cuja função é reduplicar o tema da música, intitulada "Depressão".

No final do vídeo, a mesma voz off diz apenas "solidão, meu bem". No cinema, a voz off frequentemente é a de um narrador-participante, que se dirige diretamente ao espectador, desta forma construindo um ponto de vista parcial sobre a narrativa. Neste vídeo, o uso da voz off parece servir apenas como um recurso formal na construção da sonoridade da música, que tem no enunciado "solidão, meu bem" uma espécie de refrão.

Ainda em relação à linguagem sonora, observa-se a ausência de ruídos oriundos do ambiente, criando o efeito de sentido de isolamento: os únicos ruídos são os de vozes destorcidas, que se sobrepõem à voz off e ao coro de vozes que realiza o refrão da música: "Sou psicose delirante / me transformo em cada instante / em astronauta viajante / tô na deprê / tou na depressão / não me vejo num espelho / vou andando em contramão".

Passando à letra da música, observa-se que ela se estrutura em três planos, reconhecidos com base na forma como os atores sociais são representados no discurso. Num primeiro plano, aquele do universo discursivo da protagonista, os atores sociais são individualizados através de pronomes possessivos: "minha gente favelada", "meus amigos"1; através de discurso direto: "mãe, não chore e me dê proteção"; ou ainda em sintagmas nominais com referência definida, indiretamente ligados à cantora pela estrutura da cadeia sintática ("meu sonho de menina não pode ser em vão / o que a cigana me falou / o pastor tinha falado / eu agradeci com um sorriso nos lábios"). Tanto "a cigana" quanto "o pastor" estão ligados à protagonista pela relação sintática de expansão da expressão

\footnotetext{
${ }^{1}$ Para Van Leeuwen (1996, p. 51), o uso de possessivos na representação de atores sociais indica um vínculo associativo entre os mesmos, de natureza estável.
} 
"meu sonho de menina". As estratégias discursivas são de identificação por pertencimento a um grupo social marcado simbolicamente: "minha gente favelada"; por filiação: "mãe"; por identificação funcional: "a cigana" e "o pastor".

Num segundo plano, observam-se expressões de caráter indefinido que constroem um universo discursivo antagonista: "será normal / alguém da minha idade detestar os mais clarinhos / odiar a sociedade / mas como invejo essa gente, que sem ódio nos dentes / sem amor no coração / sem bala no pente / me troca em um segundo / lá se vai a dor do mundo". As expressões "os mais clarinhos", "a sociedade", "essa gente" são codificadas léxico-gramaticalmente como alvos dos sentimentos negativos da protagonista (na letra da música "detestar", "odiar", "invejar"). Também a expressão indefinida "a malandragem" faz parte desse universo antagonista: "Eu preciso de coragem para viver nesta cidade / quero mais dignidade / descolei da vaidade / Não sou fã da malandragem". Já na expressão "quem foi eleito retribui com o dedo em nossa cara", os atores sociais representados (políticos com cargo eletivo) também são codificados como antagonistas, mas não da cantora, e sim do grupo a que ela pertence, como demonstra o possessivo: "com o dedo em nossa cara”. Finalmente, há um conjunto de expressões genéricas que remetem a atores sociais em circulação "no morro", mas que não têm ancoragem discursiva na figura da protagonista: "tanta gente morrendo", "os malandros estão matando e morrendo".

Há ainda a representação de um ator social ("não consigo o equilíbrio para lutar contra o inimigo") sem marcas de funcionalização, identificação, ou quaisquer outros traços simbólicos que permitam investi-lo de alguma concretude naquele universo discursivo. No entanto, a caracterização do ator social através de pronome definido ("O inimigo") sugere que ele é conhecido, embora não possa ser nomeado.

Destas observações, depreendem-se práticas de identificação, não com o gênero (homem/mulher) ou com a geração jovem, mas com a etnia (veja os "mais clarinhos" representados como antagonistas) e com a classe social ("minha gente favelada"). Estas identificações apontam para uma identidade oposicional, fundada num determinado sistema de poder: ao afirmar uma identidade, a cantora afirma, ao mesmo tempo, um determinado contexto (LACLAU, 2007, p. 27), o que equivale a dizer que a identidade não deve ser vista a partir de um sistema de

BALOCCO; POSTIGO - Sujeito, discurso e vida urbana... 
"diferenças" apenas, mas levando-se em conta as relações de poder constitutivas das relações sociais. Este ponto é muitas vezes negligenciado na discussão da identidade: segundo Laclau (2007, p. 27), "apenas o aspecto diferencial é enfatizado, enquanto as relações de poder nas quais ele se baseia são sistematicamente ignoradas".

As práticas de identificação da protagonista remetem a aspectos de sua subjetividade ${ }^{2}$ ("meu sonho de menina", para dar apenas um exemplo) e a aspectos de sua identidade social (entendida como pertencimento a determinado grupo social: "minha gente favelada"). É possível, assim, fazer considerações sobre a forma como o vídeo tematiza um estado psicológico (depressão, solidão, sensação de falta de perspectivas) para falar de um embarreiramento social ("Eu só preciso da verdade / paz justiça e liberdade / eu preciso de coragem pra viver nesta cidade").

Para finalizar, reafirma-se a forma como todos os recursos semióticos do vídeo, com sua estética realista, contribuem para a sua inscrição na categoria rap, cujo traço constitutivo seria o formato de denúncia social.

\section{AS ANÁLISES: O CASO DA RAPPER NA ESPANHA}

Dois videoclipes foram analisados para considerações sobre a construção de identidade da rapper Ari: "Así es la negra" e "Rap pa ti, rap pa mi”. No primeiro deles, constrói-se, através da linguagem verbal, uma identidade discursiva de mulher forte para a protagonista, com as seguintes caraterísticas: do ponto de vista físico, a mulher descrita na letra do vídeo é uma mulher negra, linda e atraente para os homens ("cuenta la leyenda de aquel que no puedo resistir su encanto"); no que diz respeito ao seu caráter, ela é corajosa, forte e segura de si ("con la mirada palante, siempre orgullosa"); no que diz respeito a experiência e atitude de vida, é descrita como esperta ("a veces peligrosa, pica como una abeja"). Ainda em relação à sua subjetividade (ou aspectos de sua identidade pessoal), a mulher representada no vídeo é apresentada,

\footnotetext{
${ }^{2}$ Segundo Fairclough (2003, p. 160), remetem a uma dimensão mais “pessoal” do eu.
} 
quanto à ideologia, orgulhosa de sua raça, do seu gênero e da sua condição social ("No soy morena, soy negra japréndetelo!", "si vuelvo a nacer quiero ser lo que ahora soy, de la misma raza, mismo sexo y condición"). Esta representação de mulher forte e segura é reforçada pela linguagem visual, que apresenta imagens de uma mulher negra de corpo atlético, correndo entre a multidão pelas ruas de uma grande cidade, perseguida por um homem branco. Ela é mais rápida do que ele, foge, para, ao final, tranquila, dar sinais de que conseguiu se safar.

Voltando à letra, a mulher representada como protagonista não está sozinha e se define através do possessivo como parte de um grupo ("con mi gente"). A pergunta que emerge aqui é, portanto: quem é a sua gente? Não há elementos para responder a esta pergunta, porém as encontramos na continuação do vídeo, quando este forma parte de uma trilogia intitulada "Bacaneria". Um segundo depois de terminado o vídeo "Asi es la negra", aparece uma imagem da cantora com um grupo de amigos dominicanos na porta de uma discoteca em algum lugar da Espanha. O segurança é espanhol e não quer deixar estas pessoas entrarem. A cena é uma discussão com frases discriminatórias por parte do segurança espanhol ("La vaina es que aquí no puede entrar gentuza") para o grupo de dominicanos (aparentemente imigrantes).

Neste contexto, "mi gente" seriam os seus amigos da mesma origem, sendo a identidade deles construída no vídeo a partir do "outro", o espanhol branco que tem o poder de decidir quem entra ou não na discoteca e que insulta o grupo da rapper, usando uma linguagem discriminatória (O problema é que aqui não pode entrar gentinha).

Como vários aspectos da identidade da cantora ficaram em aberto, foi decidido proceder-se à análise do segundo vídeo, cuja linguagem visual mostra imagens de Ari como MC nas ruas de uma grande cidade, cantando e dançando. A estas imagens, vão se intercalando cenas rápidas de outros e outras rappers dançando break dance e de imagens de tráfico e cenas da cidade.

$\mathrm{Na}$ linguagem verbal do segundo vídeo, repete-se parte das características de mulher forte e segura construídas no primeiro, sendo aqui a rapper um ator social situado totalmente num primeiro plano através do discurso direto e do uso da primeira pessoa. A caracterização física da rapper não aparece na letra, sendo sugerida neste vídeo pelas 
imagens. A figura de mulher rapper líder, rebelde e defensora da justice, se constrói com superlativos ("la diva de todos los barrios"), com repetição do nome da cantora e expressões que definem as seguintes características de sua identidade: a mulher que melhor sabe se divertir, rainha da rua e diva, com autoestima muito elevada (em toda a letra da canção); orgulhosa de sua função como Mestre de Cerimônias ("pequeña gran MC"); rebelde ("contra políticos"), revolucionária ("Yo soy la que está liando el pollo"), lutadora ("traje rimas, no traje pistola"), e líder do seu grupo ("Mi batallón se acerca").

Quanto à sua identidade social, ou de grupo, no segundo vídeo ela é a líder dos seus, construindo assim sua identidade em função de um grupo de atores sociais situados também num primeiro plano. É preciso, no entanto, definir quem é este grupo. Pelas imagens entende-se que são os seguidores do rap na rua, dos quais ela é MC: um grupo que luta contra a injustiça de forma pacífica. Para saber mais sobre o grupo e sua gente procuramos informação nas entrevistas da internet e achamos as seguintes respostas. Há dois tipos de grupo: em primeiro lugar seguidores do rap e defensores dos seus ideais, que lutam contra toda injustiça; em seguida, os dominicanos da sua condição social, que podem ser lutadores como ela ou vítimas de injustiça.

Além das características e valores que constituem a identidade criada explicitamente pela cantora nos dois vídeos, ela constrói uma identidade em oposição a "outros" (atores sociais que aparecem num segundo plano) e se define como uma mulher em luta contra "inimigos" a partir dos quais se posiciona. No primeiro vídeo, os "outros" (na letra) são, por um lado, "os homens" que a admiram e gostam dela, e por outro uma terceira pessoa indefinida de quem ela se distancia.

Há ainda referência a "inimigos" explicitamente nomeados ("Oye racista ignorante"). Também aparece um inimigo implícito que ela nomeia de forma geral "o inimigo", que pode ser a sociedade ou os responsáveis pela falta de justiça. No vídeo, o inimigo aparece como um homem branco que a persegue.

No segundo vídeo, aparecem também duas formas de nomear o inimigo. Literalmente "os políticos", que depois são chamados de "cretinos" e interpelados de forma direta. De forma metafórica, "contra 
a mareia" contra quem Ari luta pode se referir ao sistema, à sociedade, às injustiças, ou ainda aos responsáveis por elas.

Nas entrevistas da internet, achamos algumas respostas, como a seguinte: indagada "por que lutas?", Ari responde com "luto pelos meus / a minha gente e contra todo tipo de injustiça". Estas respostas sugerem que a terceira pessoa que aparece nas letras, sem nome, é o "o responsável por injustiças".

Foram procuradas mais respostas a esta pergunta nas canções "No puedo parar", "No hay héroes" e "Arriba los buscavidas", com as quais Ari mais se identifica, segundo entrevista de 2007. Nelas, aparecem "inimigos" explícitos: os fascistas, os espanhóis fascistas que invadiram o seu país; o dinheiro e a fé na religião ou em algum outro tipo de crença, política ou de outra natureza; "o Estado", "o chefe", o sistema em geral.

\section{O ENFOQUE CONTRASTIVO: MULHERES RAPPERS NO BRASIL E NA ESPANHA}

Embora encontre apoio em dados restritos e em apenas um recorte de projeto de pesquisa, a análise proposta permite teorizar sobre a constituição do sujeito e da alteridade e sobre a forma como a exclusão social é construída localmente, em diferentes cenários. Os pontos de convergência e de contraste na análise das produções musicais das rappers podem ser depreendidos das suas práticas de identificação. No que diz respeito aos contrastes, observa-se que a identidade de Ari define-se a partir de um "outro" específico ("o branco espanhol", "os racistas ignorantes"), enquanto a de Gizza jamais assume esta característica. Embora as estratégias usadas por Ari para referência aos "outros" a partir do qual constitui sua identidade sejam de assimilação ${ }^{3}$ (através do uso do artigo definido com valor de referência genérica, no primeiro caso, e do plural genérico, no segundo), essas estratégias delimitam um grupo pela identificação étnica e por valoração ideológica. A identidade

\footnotetext{
3 Para Van Leeuwen (1996, p. 48), os atores sociais podem ser individualizados ou apresentados como grupos (numa estratégia de assimilação). No último caso, podem ser representados como grupos não-especificados (estratégia de indeterminação) ou determinados (através de estratégias de diferenciação).
}

BALOCCO; POSTIGO - Sujeito, discurso e vida urbana... 
de Gizza contrasta neste ponto por definir-se a partir de um "outro" difuso ("a sociedade", "essa gente"). Observe-se que, do ponto de vista da codificação léxico-gramatical, estas são expressões genéricas sem traço de identificação ou funcionalização, numa estratégia de indeterminação. A única expressão genérica com traço de identificação em Gizza é "os mais clarinhos", que remete à raça, mas de forma suavizada: o diminutivo em português tem valor afetivo e funciona, neste contexto, como estratégia de apagamento da questão racial.

Por outro lado, em Gizza, observa-se a necessidade de uma prática de identificação que permita uma delimitação de sua identidade no interior de seu grupo de origem ("a favela"). Esta prática de identificação encontra expressão léxico-gramatical em "a malandragem" - "os malandros estão matando e morrendo" -, que marcam um "outro" que pode ser nomeado mas não identificado: o único traço de identificação deste grupo é uma expressão valorativa de caráter negativo ("os malandros"). Ou seja, as expressões constituem, neste discurso, importantes "outros" na identificação da protagonista, embora esta importância não se traduza numa estratégia de nomeação (através de diferentes formas de categorização, seja de funcionalização, identificação, diferenciação, dentre outras). Talvez o impedimento para esta nomeação possa ser encontrado na própria materialidade linguística, levando-se em consideração a forma como a expressão codifica um papel social, para este grupo, tanto ativo (como agentes em "os malandros estão matando") quanto passivo (como vítimas em "estão morrendo"). Por outras palavras, o caráter negativo da valoração codificada ("malandros") é atenuado pela representação discursiva dos atores sociais como agentes e vítimas, numa estratégia de sobredeterminação (VAN LEEUWEN, 1996 , p. 42 et seq.), que discursiviza a presença de um ator social presente na favela, mas ausente dos discursos sobre a exclusão social (ZALUAR, 1999, p. 10).

No que diz respeito aos pontos de convergência, observa-se que a ocorrência de um "outro" difuso é característica dos discursos de ambas. No entanto, as estratégias usadas pelas duas cantoras para referência a este "outro" difuso são contrastantes: no discurso de Gizza, o "outro" difuso é apresentado através de estratégias de indeterminação ("essa gente") ou de impessoalização/abstração ("a sociedade"), enquanto no de Ari, além de estratégias de impessoalização/abstração ("O Estado", "o 
sistema", "crenças religiosas e outras"), há estratégias de funcionalização ("os políticos", "o chefe") e objetivização/instrumentalização ("o dinheiro"). Ou seja, mesmo na codificação de um outro "difuso", a alteridade expressa-se de forma distinta nos dois discursos: há mais indeterminação no caso da rapper brasileira.

Estes dados apontam para características do movimento hip-hop na Espanha e no Brasil, tendo em vista a sua associação com grupos identitários de natureza diferenciada. $\mathrm{Na}$ Espanha, o intenso ritmo de crescimento da população estrangeira dos últimos anos e os problemas decorrentes da necessidade de integração desta população leva o fenômeno da exclusão social a associar-se ao fluxo migratório de grupos sociais oriundos do Leste europeu, por exemplo, da África ou das excolônias espanholas (como é o caso do grupo de Ari, constituído de negros da República Dominicana). Já no Brasil, o fenômeno da exclusão social tem raízes no sistema patriarcal brasileiro. Embora o sistema patriarcal tenha se apoiado no sistema escravocrata, há um discurso hegemônico no Brasil que nega a associação automática entre exclusão social e etnia/raça, no argumento de que "a pobreza no Brasil não tem cor" (MAGNOLI, 2007). O "outro" no discurso da rapper brasileira, portanto, não é o "racista branco" (tal como representado discursivamente em Ari), mas um "inimigo" difuso, "essa gente", "a sociedade".

Resultados conclusivos em relação a estes pontos exigem um corpus mais abrangente, representativo do movimento hip-hop nos dois países. No entanto, no que diz respeito às práticas de identificação das cantoras na dimensão de gênero, é possível apontar a ausência de estereótipos do masculino ou do feminino no discurso de Gizza, embora eles possam ser observados no de Ari: a representação discursiva da mulher nas duas canções encontra apoio em significantes do feminino de natureza estereotipada (com base na aparência física), embora haja também alguns significantes fora do escopo desses estereótipos (mulher segura e confiante). Para Ari, portanto, os eixos raça/etnia e gênero são igualmente importantes na afirmação da identidade de rapper na Espanha, enquanto para Gizza a questão da condição social sobrepõe-se à do gênero. De fato, em entrevista colhida na internet, a cantora afirma que "escrev[e] sobre a realidade, não gost[a] de levantar a bandeira feminina [...], não fa[z] letra contra o machismo, [e] pref[ere] denunciar o 
sofrimento das mulheres da periferia". Ainda segundo a autora, "o rap é $100 \%$ protesto, denúncia e transformação".

Para finalizar, levanta-se a seguinte questão: de que forma os discursos das cantoras representam discursivamente a diferença social? Tanto em Gizza quanto em Ari, as diferenças sociais são acentuadas, numa estratégia de construção discursiva da "exclusão" como uma afirmação da diferença. Assim, a identidade das cantoras articula-se constitutivamente na referência a um "outro" que, se por um lado marca o lugar da diferença, por outro é a condição de possibilidade para a emergência de sua própria identidade de rappers.

A identidade oposicional em determinado sistema de poder é ambígua em relação àquele sistema, pois se é o sistema que impede a constituição plena daquela identidade, ele é, ao mesmo tempo, sua condição de possibilidade. A afirmação de uma identidade oposicional para as rappers pressupõe a articulação, no seu discurso, de uma "tarefa" de representação universal (as demandas de representação de seus grupos de origem), mas sua identidade não se esgota naquela tarefa. Pelo contrário, a política de identidades do movimento bip-hop não se funda no "essencialismo" (que estabelece uma relação necessária entre sujeito e identidade), mas deve ser entendida, isto sim, como uma articulação estratégica, que aponta para seus próprios limites e sua contingência, haja vista a forma como o movimento é apropriado diferencialmente em contextos sociais diversos e como constrói, de forma distinta, a noção de exclusão social.

\section{REFERÊNCIAS}

ANDRINGA, E. et alii. Point of view and viewer empathy in film. In: VAN PEER, W.; CHATMAN, S. (Orgs.). New perspectives on narrative perspective. Albany: State University of New York Press, 2001.

FAIRCLOUGH, N. Analysing discourse: textual analysis for social research. London: Routledge, 2003.

HERSCHMANN, M. O funk e o hip-hop invadem a cena. Rio de Janeiro: UFRJ, 2005. 
JANOTTI JR., J.S. Heavy metal: o universo tribal e o espaço dos sonhos. 1994. 126f. Dissertação (Mestrado em Multimeios) - Instituto de Artes, Universidade Estadual de Campinas, Campinas, 1994.

KRESS, G.; VAN LEEUWEN, T. Multimodal discourse: the modes and media of contemporary communication. London: Arnold, 2001.

LACLAU, E. Emancipation(s). London: Verso, 2007 [1. ed. 1996].

MAGNOLI, D. Estatísticas no pau de arara. O Globo, Opinião, Rio de Janeiro, p. 7,8 fev. 2007.

MATIAS, A. A era de ouro do videoclipe: algumas palavras sobre a TV e a internet. Disponível em: <http://www.cultura.gov.br/foruns_de_cultura/ cultura_digital/na_midia/index.php?p+23469\&more $=1 \& c+1 \& p b+1>$.

MENDONÇA, C.M.C. Moda, estilo de vida e videoclipe: aspectos da cultura hip-hop. In: CONGRESSO BRASILEIRO DE CIÊNCIAS DA COMUNICAÇÃO, 26., 2003, Belo Horizonte.

OLIVA, R. O intervalo comercial da MTV pelo viés da fragmentação e pós-modernidade. 2005. 83f. Dissertação (Mestrado em Comunicação) Faculdade de Comunicação, Educação e Turismo, Universidade de Marília, São Paulo, 2005.

PEREIRA, V.H.A. Novas pedagogias do oprimido: a arte e a cultura como instrumentos e construção de sujeitos subalternos. In: JOBIM, J.L.; PELOSI, S. (Orgs.) Identidade e literatura. Rio de Janeiro: Instituto de Letras; Roma: La Sapienza, 2006.

PONTES, P. Linguagem dos videoclipes e as questões do indivíduo na pósmodernidade. Sessões do imaginário, Porto Alegre, n. 10, 2003.

RAJAGOPALAN, K. A construção de identidades e a política de representação. In: FERREIRA, L.M.A.; ORRICO, E.G.D. (Orgs.). Linguagem, identidade e memória social. Rio de Janeiro: DP\&A, 2002.

SOARES, T. Videoclipe, o elogio da desarmonia. Recife: Livro Rápido, 2004.

VAN LEEUWEN, T. The representation of social actors. In: CALDASCOULTHARD, C.R.; COULTHARD, M. Texts and practices: readings in Critical Discourse Analysis. London: Routledge, 1996.

VENTURA, T. Notas sobre política cultural contemporânea. Revista Rio de Janeiro, n. 15, p. 77-90, jun./abr. 2005. 
ZALUAR, A. Um debate disperso: violência e crime no Brasil da redemocratização. São Paulo em Perspectiva, São Paulo, v. 13, n. 3, p. 3-17, jul./set. 1999. Disponível em:

$<$ http://www.scielo.br/pdf/spp/v13n3/v13n3a01.pdf> . Acesso em: 25 mar. 2007.

ZIZEK, S. Interrogating the real. London: Continuum, 2005.

\section{VIDEOCLIPES ANALISADOS}

NEGA GIZZA. "Depressão" (5,03 min.). Disponível em:

$<$ http:/ www.youtube.com/watch?v=u8SjHXoJOLY>.

ARIANNA PUELLO. “Así es la negra” (1,33 min.). Disponível em: $<$ http://es.youtube.com/watch?v $=\mathrm{mn} 34 \mathrm{nWc5tV4}>$.

ARIANNA PUELLO. "Rap pa ti, rap pa mi”" (3,19 min). Disponível em: $<$ http://es.youtube.com/watch?v $=$ XXhdzyjHpk0>.

\section{ANEXO}

\section{“Depressão" (Nega Gizza) ${ }^{4}$}

A que horas necessito sair, vou me arrumar, não posso me esconder, vou continuar

Uma interrogação sobrevoa minha mente, não vou voltar, vou seguir em frente

Meu Deus, por que o mal está prevalecendo? Tanto sofrimento, tanta gente morrendo

Sinto uma grande vontade de voltar, se parar a morte leva, precisamos caminhar

\footnotetext{
${ }^{4}$ Letra transcrita do vídeo indicado nas referências. Os pontos de interrogação entre aspas indicam dificuldade de apreensão do sentido, por parte da pesquisadora. Os pontos de escansão indicam a estrutura musical da canção.
} 
Vou me despir do preconceito, vou buscar o meu direito, desabafar do peito

Esse mundão ainda tem jeito, um rio desce do meu rosto sem eu sentir

Deságua na ansiedade, vou (??) prosseguir

Eu só preciso da verdade, paz, justiça e liberdade

Eu preciso de coragem pra viver nesta cidade, quero mais dignidade, descolei da vaidade

Não sou fã da malandragem e vou vivendo, os malandros estão matando e morrendo

A pressão tá aumentando, tá ficando tudo escuro, vou alinhar o meu futuro

[Refrão] Sou psicose delirante, me transformo em cada instante em astronauta viajante

Tô na deprê, tou na depressão, não me vejo num espelho, vou andando em contramão

Afundei na droga, não importa qual, variando uma dose (?) entre o bem e o mal, será normal

Alguém da minha idade detestar os mais clarinhos, odiar a sociedade

Mas como invejo essa gente, que sem ódio nos dentes, sem amor no coração

Sem bala no pente, me troca em um segundo, lá se vai a dor do mundo

Minha alma tá morrendo com meu sonho vagabundo

Adrenalina vai a pique, é difícil me conter

Tô deprimida, vou enlouquecer

Perco a noção, desconheço meus amigos, não consigo o equilíbrio pra lutar contra o inimigo

Mãe, não chore, me dê proteção

Meu sonho de menina não pode ser em vão

O que a cigana me falou, o pastor tinha falado, eu agradeci com um sorriso nos lábios

Mas e daí? Se não consigo ser curada

Felicidade não é viver angustiada

Sonho acordada, não é isso que eu queria, me perder na madrugada e me encontrar no dia 
[Refrão] Sou psicose delirante, me transformo em cada instante em astronauta viajante

Tô na deprê, tou na depressão, não me vejo num espelho, vou andando em contramão

A depressão quer me pegar, me levar, me torturar, mas não posso me entregar, mas não posso me matar

Explorados neste morro feito sacos de pancada, quem foi eleito retribui com o dedo em nossa cara

Refém da solidão, eu continuo aqui trancada, me escondi da depressão mas fui encontrada

Quem pode me dizer se tou perto de morrer

$\mathrm{E}$, se morrer, será que vou subir ou descer?

Reprimida dos pés à cabeça, sou fiel, atrevida com homens (??), valente, eu tou no céu

Meu crime foi falar pela minha gente favelada

Não quero ser julgada sem ter advogada

Tô exausta, várias noites sem dormir

Mas antes no final da vida decidir se vou sair [Voz em off]: até que você gire,

Por enquanto eu fico aqui você gire, gire, gire

[Voz em off] Solidão, meu bem

[Refrão] cantado em voz off, em sussurros: Sou psicose delirante, me transformo em cada instante em astronauta viajante

Tô na deprê, tou na depressão, não me vejo num espelho, vou andando em contramão

\section{“Asi es la negra” (Arianna Puello)}

Mira la negra donde va con ese cuate, la reina del mambo domina las calles, pobre de aquel que se le acerque y le ladré, jay mi madre! Menudo desmadre, que quién es ella preguntan por ahí, cuenta la leyenda de aquel que no puedo resistir su encanto, por la acera al caminar, chicha por 
delante, chicha por detrás, marcando el paso al ritmo de la vida, sus ojos negros ni un detalle descuidan, sabe que en la jungla no se puede despistar, se puede hablar pero nunca confiar, clara como el agua le gustan las cosas, con la mirada pa'lante, siempre orgullosa, a veces tranqui, a veces peligrosa, pica como una abeja, vuela como una mariposa. Así es la negra jesa negra!

[Refrão] La negra tiene tumbao, tumbao. Y no camina de lao, de lao. La negra tiene tumbao,tumbao. Mírala por donde va, jesa negra!

No soy morena, soy negra japréndetelo! No te equivoques conmigo ¡recuerdalo!Oye racista ignorante, asúmelo. Vas a tener que aguantarme, si vuelvo a nacer quiero ser lo que ahora soy, de la misma raza, mismo sexo y condición, saber resolver siempre la situación, poner los pies en la tierra, saber pedir perdón, aprovechar la ocasión, pensar en pasta sin exageración, pasar los días viajando con mi gente, que la rutina se convierta en algo diferente, y es que la salud está en la mente, por eso estoy bien, por eso soy fuerte, si quieres algo de mi ven a hablarme, si quieres algo de mi ven a verme

[Refrão] La negra tiene tumbao, tumbao. Y no camina de lao, de lao. La negra tiene tumbao,tumbao. Mírala por donde va, jesa negra!

A mi me gustan las cosa bien hechas, debo ser letal como una fecha, porque el enemigo siempre te acecha, no van a robarme toda mi cosecha, la negra siembra pa luego recoger, si tu semilla no germina, prueba otra vez, que tú a lo tuyo, que yo a lo mío, de esta manera evitaremos lío, si quieres algo de mi ven a verme, a veces tranqui, a veces peligrosa, pica como una abeja, vuela como una mariposa, así es la negra, ¡esa negra!

[Refrão] Ahí viene la negra, venga, échate pa un lao, no ves que esta negra llega y domina el tumbao.

"Rap pa ti rap pa mi” (Arianna Puello) 
A ver kien es la hija de puta ke mas disfruta en el escenario con todos ustedes y ojalá así sea a diario... Arianna puello búscame en el diccionario, la reina la diva de todos los barrios yo traje el rap ke representa las calles cuando esta mierda suene políticos se callen no kiero oír ni un comentario irracional, por qué no son negocios es algo personal. Así ke traje rimas, no traje pistola... ando acompañá mi gente no me deja sola. Esto está ke arde y yo vengo prendía... contra marea la humanidad es mía porke me gusta disfrutar de la vida, vente conmigo si kieres movida. Mi batallón se acerca en forma de estampida, armando jaleo por toda la avenida.

[Refrão] ... rap pa mi, rap pa ti... (x2)

Rap fenómeno ya sabes a lo grande... mi rimas te pican en enjambre así ke... vamos cabrón mueve el melón... esto es rap en español disfrútalo!!!! porke soy yo la ke esta liando el pollo... Arianna puello pim pam!!!! pimpollo. Te la estás comiendo doblas, en menos y en ná no te quedes atrás... King kong es una mierda comparado conmigo... pekeña gran mc... prepárense cretinos mi rap es una plaga no podéis hacer nada motor en marcha, este tren ya no se para... porke aquí no nos vendemos por dinero... somos humildes, honrados y sinceros. Un saludito para todos los pobres... ke nunca falte de ná, ke siempre sobre. Esto se extiende... esto se esparce... puro rap latino por todas partes esta ke arde, esta ke arde!!!! venga vamos... continua con el desmadre!!!!

[Refrão]... rap pa mi, rap pa ti...

Recebido em 18/07/08. Aprovado em 10/01/09.

Title: Subject, discourse and urban life: a contrastive study of discourses on social exclusion in Brazil and in Spain

Author: This is a contrastive study of discourses on social exclusion through the analysis of videoclips produced by female rappers in Brazil and in Spain, from the perspective of Critical Discourse Analysis and with a focus on the construction of identity. Analysis of the identification practices of the rappers suggests that alterity is expressed in distinct ways in their discourses: while in the Brazilian rapper's discourse, the "other" is articulated through lexicogrammatical strategies of indetermination ("people") or abstraction ("society"), in the Spanish rapper's the strategies are of 


\section{4}

functionalization ("politicians") and objectivization ("money"). In other words, there is more indetermination of the "other" in the case of the Brazilian rapper.

Abstract: Anna Elizabeth Balocco; Maria Labarta Postigo

Keywords: gender, identity, social exclusion, music, videoclip

Titre: Sujet, discours et vie urbaine: une étude qui marque l'aspect divergent du discours sur l'exclusion sociale au Brésil et en Espagne

Auteur: Anna Elizabeth Balocco; Maria Labarta Postigo

Résumé: Dans cet article, on présente une étude qui marque l'aspect divergent du discours sur l'exclusion sociale à travers l'analyse de vidéoclips produits par des femmes rappers au Brésil et en Espagne, selon les principes de l'Analyse Critique du Discours et avec focalisation dans la construction de l'identité. L'analyse des pratiques d'identification de rappers suggère que l'altérité s'exprime de manière distincte dans les deux discours: pendant que «l'autre» s'articule, dans le discours de la rapper brésilienne, à travers des stratégies lexico-grammaticales de l'indétermination («ces gens ») ou abstraction (« la société »), par contre, dans celui de la rapper espagnole il y a des stratégies de fonctionnalisation ( les hommes politiques») et objectivation («l'argent»). C'est-à-dire, il y a plus d'indétermination de «l'autre » en ce qui concerne la rapper brésilienne.

Mots-clés: genre social, identité; exclusion sociale; musique; vidéoclip.

Título: Sujeto, discurso y vida urbana: un estudio contrastante de discursos sobre la exclusión social en Brasil y en España

Autor: Anna Elizabeth Balocco; Maria Labarta Postigo

Resumen: En este artículo, se presenta un estudio contrastante de discursos sobre la exclusión social a través del análisis de vídeo-clipes producidos por mujeres rappers en Brasil y en España, según principios del Análisis Crítico del Discurso y con foco en la construcción de la identidad. El análisis de las prácticas de identificación de las rappers sugiere que la alteridad se expresa de forma distinta en los dos discursos: mientras que el "otro" se articula, en el discurso de la rapper brasileña, a través de estrategias léxicogramaticales de indeterminación ("esa gente") o abstracción ("la sociedad"), en el de la rapper española hay estrategias de funcionalización ("los políticos") y objetivización ("el dinero"). O sea, hay más indeterminación del "otro" en el caso de la rapper brasileña.

Palabras-clave: género social; identidad; exclusión social; música; vídeo-clipe.

BALOCCO; POSTIGO - Sujeito, discurso e vida urbana... 